\title{
Leadership First: Reimagining DEI Together
}

\author{
Dr. Linda Ellington \\ Professor of Business, Southern New Hampshire University, Manchester, USA \\ *Correspondence: Dr. Linda Ellington, 1.ellington@snhu.edu
}

ABSTRACT: This article is a thoughtful integrative compilation of literature from scholars well known in their field of diversity, equity, and inclusion all of whom have brought welcome changes for the next generations. There is a new look to DEI and leadership matters. Even prior to the pandemic, the future of work was unfolding. Organizations continue to focus on digitalization, remote work, employee empowerment and workforce diversity. Similarly, leaders are reinventing themselves to transform through the ability to traverse a path of immense changes adapting to global trends and consumer preferences.

KEYWORDS: Diversity, Equity, Inclusion, Leadership, Intersectionality, Workplace Cultures

ARTICLE INFORMATION
Author(s): Dr. Linda Ellington
Received: 07 Nov, 2021; Accepted: 16 Dec, 2021; Published:30 Dec,2021;
e-ISSN: 2347-4696;
Paper Id: BMN-IJBMR-2021-77;
Citation: doi.org/10.37391/IJBMR.090410
$\begin{aligned} & \text { Webpage-link: } \\ & \text { https://ijbmr.forexjournal.co.in/archive/volume-9/ijbmr-090410.html }\end{aligned}$

\section{INTRODUCTION}

Reimagining diversity, equity, and inclusion (DEI) has become a high priority and central in diversity literacy strategy. Leaders within all industries have realized that an inclusive workplace where employees feel they can be their authentic selves was necessary to attract the best talent and foster greater innovation. Although your organization is uniquely positioned to host DEI initiatives, strategies, and trainings virtually, there are still many lessons to be learned.

\subsection{Managing Diversity is at the Core of Leadership}

Scholars suggest managing diversity is a high priority issue for organizations, which basically means planning and implementing organizational systems and practices to lead people to achieve their full potential unhindered by group identities such as gender, race, nationality, age, and departmental affiliation. These same scholars suggested that managing diversity is crucial to the accomplishment of organizational life and should be of paramount concerns to leaders.

Opportunity is thought to be the direct legacy of the civil rights and feminist movements and the landmark Civil Rights Act of 1964. Yet, as Frank Dobbin showed, corporate personnel experts - not Congress or the courts - were the ones who determined what equal opportunity meant in practice, designing changes in how employers hire, fire, promote, and ultimately defining what discrimination is, and is not, in the American imagination (2011).

It is helpful to offer some basic definitions as a foundation to understanding DEI. Three operationalizations capture the essential aspect of the DEI terrain (Cooperative Extension, n.d., para. 1-3, as cited in Pompper, 2021):
- Diversity is the presence of differences that may include race, gender, religion, sexual orientation, ethnicity, nationality, socioeconomic status, language, disability, age, religious commitment, or political perspective. Populations that have been and remain underrepresented among leaders in their field and marginalized in the broader society.

- Equity is promoting justice, impartiality and fairness within the procedures, processes, and distribution of resources by institutions or systems. Tackling equity issues requires an understanding of the root causes of outcome disparities within a society.

- Inclusion is an outcome to ensure those that are diverse actually feel and are welcomed, Inclusion outcomes are met when the organization's policies and practices are truly inviting to all. To the degree to which diverse individuals are able to take part fully in the decision-making processes and development opportunities within an organization or group.

In a recent podcast, research professor Brown described diversity as character traits that reflect protected class identities, often factors that lead to disparities (Brown and Bethea, 2020). While these definitions of diversity suffice to start the conversation, like the popular metaphor of diversity representing being invited into a space (a meeting, a party, or a dinner), one must also remember that diversity may become diluted, that leaders may become distracted, by this weakening. To combat this effect, Noel (2003) offered scientific evidence from the Harvard Implicit Association Test and compelling imagery to help predominantly White audiences to see Black men differently. This leads to the next important definition, inclusion. Many scholars focused on inclusion suggested, metaphorically, that if diversity is (identity-based) being invited into the space, then inclusion is being engaged in the activity by those who created the context.

And yet, according to Souba and Souba (2016) we can generate all sorts of definitions on explaining or interpreting how DEI works, but yet often leaders can only approximate the actual phenomena of diversity being examined. Many disagreements, arguments, fights, and wars are the result of relying on a reality that does not represent what is actually going on in an organization. Leaders think they are having the real conversation but are depending on their frame of reference 
and their definition of DEI in connection to the meaning of leadership.

\subsection{Leader's Limitations of Talk}

Diversity, inclusion, and bias can be sensitive topics that are difficult to talk about, especially at work. We are at a time when we do not know how to talk about sensitive topics. We have been taught to avoid them and now they are staring us in the face (Gordon, 2021). In her book, Addressing Unconscious Bias at Work, Gordon quoted Winston Churchill, "If you are going through hell, keep going," and we have not kept going in addressing the issues of diversity. We keep stopping because the road is tough, the conversations are uncomfortable, and the realization that what we have been doing for many years may have been wrong is difficult for leaders to face (p. x). We need to debunk the myth that the concept of diversity is a one-size-fits all solution. Often business leaders make excuses and use them as a shield to absolve them of their duty as leaders.

Gordon (2021) pointed out excuses she hears quite often when consulting with leaders:

- Diversity does not work.

- I do not see color.

- We just hire the best without regard to gender or race.

- We do not want to lower the bar on job requirements.

And yet, we should find these statements troubling. Are they barriers to diversity by creating a culture where the status quo is acceptable? Do these statements create roadblocks to innovation by stifling leaders who to want to harness the creativity of their workforce but are not able to?

How leaders react, not what is said, sometimes creates crosscultural misunderstandings because of differences in experiences, interpretation, and thinking. As Lipman posited, it is not that people have a precise view of the world and communicate it vaguely; instead, they have a vague view of the world (2009). The word Ubuntu from the Bantu language of South Africa literally means "I am because we are." It highlights the fact that we cannot exist independent of our relationships with others. Not only do we need others, but we need to feel that they are human so that we can feel human too. As such, Ubuntu highlights one implication of harming others, that one's own humanity is reduced when others are treated without dignity and respect. From this perspective, inhuman behavior not only reflects the ways in which victims are treated but also the qualities of those who perpetrate against them (Bastian et al., 2012). Causing harm to another person may also affect perceptions of the self. In fact, from the perspective of the perpetrator, viewing the self as less human in response to interpersonal transgressions may be an appropriate and normal response. It reflects the understanding that one's humanity is dependent on the humanity of those around us. Indeed, it may be a failure to engage with the selfdehumanizing consequences of one's own actions - a failure to apply the concept of Ubuntu - that is most concerning when we consider the actions of those that harm others (Bastian et al., 2012, p.156).
Simpson (2008) noted, "Dialogue at its best is an interaction among people that produces something greater than the sum of its parts and leaves participants changed by that interaction" (p.139). The process of dialogue itself is valuable, not just as a means to reach a solution (Heath et al., 2006; Simpson, 2008). It allows participants to challenge their preconceived motions and create a shared meaning with one another, even if an action plan is not created. Successful dialogue also requires that its participants be willing to engage, suspend their own beliefs, and seek to understand those with different perspectives (Heath et al., 2006).

There is an opportunity to bring together structural constructs of race and the lived experiences (Halualani et al., 2006). Structured difficult dialogues provide a platform for these types of communicative actions to take place and more productive conversations about diversity forward. One such platform is identified by Ramusabramanian et al., which is a goal-based dialogue model to facilitate difficult dialogues in a variety of applied communication contexts (2017).

Let us challenge colonialist narratives through critique and by including multiple perspectives on these issues and go beyond the Westernize thinking about the global set of concerns by incorporating new voices (Schwabeland et al., 2015).

\section{DEI COMMITMENT WITH ACTION}

Do not wait until the sirens sound. There is a culture of silence and until leaders open conversations up to everyone, the consequence of employee silence is isolation which can stifle an organization's initiatives or derail meaningful progress while increasing loss of critical talent through alienation and attrition, creating a turnover tsunami.

Leaders need to hear the voices bubbling up in their organizations. It is not enough to have DEI statements and campaigns posted throughout an organization, there needs to be shared, documented, and showcased for what an organization stands for in DEI and then publicly what will be done to sustain DEI practices for the long term. One of the biggest issues that is facing leaders is that often DEI strategies are viewed as a 'check box.' They believe that providing a statement on diversity or announcing diversity as a goal is sufficient. This is where actions speak louder than words and this is where a leader's integrity comes into play. By not being aware of different perspectives, approaches and experiences, individuals may be unable to understand the complete picture of what is going on, which may in turn create even more tension and missed opportunities to learn and acknowledge different points of view (Logan, 2021).

There are everyday actions leaders can take to cultivate an inclusive organization (Perry, 2018). It is virtually impossible to be successful in one's work in any kind of group - be it a corporation, a deep-sea fishing crew, or a rock and roll band without feeling a sense of belonging. Most of us have had the 
experience of working where we did not really fit in, and sure we can pull in that paycheck for a while, make do, hang in there, but how long do those jobs ever last, especially if we want to be honest with ourselves or have a healthy work-life balance? Leaders and aspiring leaders who want to succeed need to harness the synergy of belonging (Perry, 2018). Cultivating a workplace where everyone can show up authentically and feel valued and respected for their contributions, must be more than a leader's check box mindset. Recognizing our collective responsibility to earnestly address our differences and increase understanding and empathy will not only enhance organizational goals but will also lead to a healthier, kinder, and more compassionate world (Winters, 2020).

Leaders need to explore barriers to the authentic adoption of diversity, equality and inclusion and achieving authentic DEI is a primary responsibility that leaders have yet to fulfill (Pompper, 2021). Breaking down barriers to the authentic adoption of DEI is vital for twenty-first-century leaders who want to assume the challenging, but rewarding, work of engaging in the kind of insider activism necessary to lead organizations to embrace one of their most important responsibilities in actualizing DEI. Leaders need to produce the necessary courage in people to take on the status quo. It must be hittable enough so that it shows up for people as feasibly solvable and they simultaneously show up for themselves as capable of tackling it. And the new future must be inspirational enough to unite and align them so that their decisions and actions can be coordinated efficiently and effectively (Souba \& Souba, 2016).

\section{THE TOOLKIT FOR LEADERS}

Spranger (2021) identified the first step is to acknowledge that structural racism, sexism, and other biases exist. There is a collective responsibility, especially for those in places of power and privilege, to dismantle these inequalities. One must then recognize their own privilege, taking a critical eye to one's own identity and how one has benefited from a system that oppresses so many others (Worsham et al., 2021). With this, one can assess how this plays out within their own organization and learn how to make room for everyone (Pai, 2020).

\section{Tool 1: Hire inclusively}

The notion of unconscious bias from majority white male leaders means that the lack of diversity in leadership positions is a self-perpetuating problem. To break this cycle, leaders need to engage in inclusive hiring activities by employing staff and leaders from marginalized groups that have previously faced discrimination. This helps to fast-track DEI and to reform archaic systems. Intersectional gender issues and the crossovers between social identities must also be considered when hiring staff. Nonetheless, there are many ways to deploy inclusive hiring incorrectly. For example, hiring someone for a role above their capabilities and not giving them the required support to acclimatize sets that person up for failure and perpetuates discriminatory assumptions. The glass cliff has been termed to describe when black, indigenous and people of color (BIPOC), particularly BIPOC women, are brought into leadership roles when organizations are in crisis. This results in low likelihoods for tenure, greater obstacles for success than white counterparts, and if you do fail, you play into all the stereotypes about women in leadership. This does not create a work environment where the person feels included and welcomed, thus increasing staff turnover and risking performance challenges.

\section{Tool 2: Remove gendered barriers}

Since women have not always been in the formal workplace, it is fundamentally designed for men. Promotions are often awarded on working extra hours, socializing after work, and years spent at a company without breaks, which is harder to do when you have the reproductive burden of pregnancy, birthing, and childcare. Sexual harassment, unmet sanitation needs in the workplace, and gender stereotypes have also been recorded as placing substantial burdens upon women's career progression (Slater, 2020).

This workplace disparity can be leveled out through equality in salary, paid paternity and maternity leave, flexible working hours, spaces for breastfeeding, onsite laundry facilities, and nurseries or after-school clubs for worker's children. One study conducted by Hoobler et al., into the underrepresentation of women in upper management found that female managers were grateful for organizational policies that enabled them to take time off or reduce their hours for family responsibilities. However, they also felt that reduced or flexible time took a toll on their careers (2011). This highlights that policy change may have its limitations and that our views on domestic responsibilities need to adapt simultaneously to achieve gender equality in the workplace.

\section{Tool 3: Cultivate an inclusive environment}

Through the training and education of leaders and staff on the importance of DEI, an equitable and inclusive workplace culture can be promoted, wherein all persons feel welcome and heard. Many recent studies have shown that efficiency and innovation increase in organizations where everyone feels included and respected equally (Hunt et al, 2018). For access to leadership positions to be equitable, those in positions of power must become vocal advocates for marginalized groups, who are more likely to be from lower socioeconomic backgrounds and invest money and resources into training those staff. Efforts should also be spent on highlighting clear paths to leadership for such groups (Allen et al., 2021).

\section{Tool 4: Leader's Act of Phronesis}

A leader's integrity is a mountain with no top. Therefore, those who set off on this task must learn to enjoy climbing because there is no end to the process. And as the climb continues organizational life continues to get better (Erhard et al., 2011).

Phronesis is the practical intelligence in determining ends and the means of attaining them, practical understanding, and sound judgment, with integrity threaded throughout the fabric 
of a leader. Russell (2012) wrote about the Aristotle approach relevant to the relationship between practical intelligence and the virtues of character. He argued that virtue ethics cannot survive without the thesis that phronesis, much as Aristotle conceived of it, is a crucial part of leadership virtues. In his book, Practical Intelligence and the Virtues, Russell does not hide from the contemporary controversies surrounding the view that phronesis is necessary for virtue. Noel (2003) wrote in the Journal of Philosophy of Education that phronesis is teaching with wisdom and imagination, and leaders are teachers. Even those who criticize phronesis because of its rigidity, it helps to develop a richer account of leaders who are ethical throughout their decision making.

Slote (2001) created controversy in his book, Morals from Motives. He wrote that he agrees with the criticism that Aristotle's doctrine of the mean has no way of dealing with virtues that never distinguishes between what it would be morally good for us to do for others, and what we actually have an obligation to do for them.

Aristotle language implies that the virtuous individual does what is noble or virtuous because it is noble - for example, having courage to do this simply is because the virtuous individual actually will choose or has chosen it. However, Aristotle also recognizes those non-virtuous individuals can perform good or virtuous acts under the direction of others and, in addition, he characterizes the virtuous individuals as someone who sees or perceives what is good or right to do in any given situation (Slote, 2001).

The basic shape of wisdom is taking the right actions that then develop a sound judgment for assessing those actions for adequacy without begging any questions against them. However, questions do need to be asked:

Should leaders take seriously the idea that the virtue of wisdom has anything to do with rightness, and the role of consequences and outcomes in their actions? Does it depend on what conditions are necessary and sufficient for an account of right actions to count as a kind of leadership? (Russell, 2012)

People often describe phronesis as a leadership action that is right if and only if it is what a virtuous character would do in the circumstances. Nonetheless, virtue ethicists in recent years have increasingly retreated from ideas about what the virtuous leader would do. Fink goes further into this idea of a virtuous leader in his book, Phantasia in Aristotle's Ethics, which he posited if the integration of character virtue and phronesis is successful they mutually depend on each other; you cannot be a good leader in the true sense of the word without practical wisdom nor be practically wise without virtue of character (2019).

\section{Tool 5: Develop Organizational Culture}

It is important to develop an organizational culture that is selfreflective and open to change, giving a platform to staff from marginalized groups to voice concerns over the current systems (Paige, 2021). Organizations should collectively discover the best practices and develop innovative solutions to improving DEI. Leaders and staff must continue to educate themselves and each other on the complexities of systematic oppression both within organizations and in other aspects of their lives. DEI programs are more successful if the involved parties agree with them. Therefore, it is necessary that staff discussions and training on the importance of DEI in conjunction with complementary approaches (Lambouths et al., 2019).

According to Lambouths et al., they found that since the 1980s, companies have increasingly adopted diversity policies to improve the representation of women and racial minorities in the workplace. Today over $95 \%$ of companies with at least 1,000 employees have instituted programs to increase diversity and inclusion within their ranks (Lambouths, et al., 2019). Despite this, we know remarkably little about how people feel about these programs, and even less about why they feel the way they do. This is a major knowledge gap. They also discovered through their research that diversity programs are more effective when workers support them - and when done correctly, they offer great opportunities to improve workplace equity and, ultimately, a more productive organization. At their worst, however, they can stimulate resistance and actually create an even more challenging environment for underrepresented workers. If there is a virtuous doctrine such as Aristotle described, then there is no way of dealing with virtues like truth-telling and promise keeping or even DEI philosophies in a leader's creed. Although Aristotle mentioned the fact that we tend to praise lovers of humankind, his theory of virtue does not seem to deal with a concern for human beings generally, meaning all of humankind, thus DEI imperatives (Slote, 2001).

\section{Tool 6: Diversity Literacy Strategy}

A literacy strategy is to be led by organizational leaders from different background as well as individuals from majority groups with varying levels of expertise and varying levels of cultural fluency. Many scholars have suggested dialogue as a means to respond to issues of racism (Simpson 2008; Sue, 2013; Sue and Constantine, (2007).

Without a doubt, there are implications for several applied settings; several business organizations in White-dominated occupations in particular have placed a greater emphasis on diversity and inclusion, not just in terms of recruiting more racial/ethnic minorities but also finding ways to help them succeed and thrive. An important aspect of building community, be it in business or other types of organizations, is to create an open welcoming climate where employees and coworkers feel comfortable to have honest conversations about important yet challenging topics. Diversity literacy is an integral aspect of successful leadership. Ramasubramanian, et al., identified a framework to promote important skills such as active listening, empathy for others, and openness to diverse viewpoints, which can be applied to a varity of organizational settings (2017). 
Based on their research (Ramasubramanian et al., 2017) found that it is important to take a goal-based social identity approach to designing such dialogues by selecting appropriate communication elements (such as localized vignettes, shared ground rules, trained facilitators, and role-play techniques) to suit the differing needs and goals of the racial/ethnic identifies. When designed well such approaches can encourage critical thinking, to reflect on diverse perspectives, create greater empathy, help form alliances across multiple groups to work collectively towards a common goal and motivate everyone to make a personal commitment to be agents of change within their circles of influence (p. 18).

\section{CONCLUSIONS}

The aim of this article was to share produced knowledge by recognized scholars in their insights to the value DEI plays beyond accessing new ideas but increasing the orientation of stagnant organizations through infusion of talent and skills, which will trigger a cultural change to more proactivity and greater risk tolerance.

Because leaders are those who are brokering the meshing of the old and the new - such leadership is a matter of bridgework as well as trailblazing the right actions in reimagining the DEI climate. The crisis of climate change impacting the planet is well known to many but let us not ignore the climate change needed in DEI. If we do nothing, the cost will be too high. Creating the bridge between what is genuinely needed may be challenging for many leaders, but yet the commensurate with new practices and policies is going to occur, which just might displace those leaders not willing to roll up their sleeves and do what is right in the area of DEI.

The story that emerges out of the collection of the perspectives of scholars is not doom and gloom but neither is it a smooth transition to some utopian new paradigm world. We need to look honestly at the difficulties before us, as well as at the positive and potentially realizables goals. And we need to admit that no one can be certain of the full pattern of these changes. At the heart of this perspective is the conclusion that the role of business on the planet is shifting - must shift, if the global goal is to seek diversity, equity and inclusion together (Harman et al., 1997).

Leaders need to have the courage to foster conversations with change-catalysts, culture-shifters, and more than a few troublemakers who are innovating, creating, and daring to lead (Brown, 2018).

\section{REFERENCES}

[1] Allen, J. M., Abdul-Mutakabbir, J. C., Campbell, H. E., \& Butler, L. M. (2021). Ten recommendations to increase Black representation within pharmacy organization leadership. American Journal of Health-System Pharmacy, 78(10), 896-902.

[2] Bastian, B., Jetten, J., Chen, H., Radke, H.R.M., Harding, J.F., Fasoli, F. (2012). Losing our Humanity: The Self-Dehumanizing
Consequences of Social Ostracism. Psychology Bulletin, 39(2) 156-169. Sage Publications.

[3] Brown B. (2018). Dare to Lead: Brave work. Tough Conversations. Whole Hearts. Random House.

[4] Brown, B \& Bethea A. (2020). Inclusivity at work: The Heart of hard conversations. Retrieved from https://brenebrown.com/podcast/brene-with-aiko-bethea-oninclusivity-at-work-the-heart-of-hard-conversations/

[5] Dobbin, F. (2011). Inventing Equal Opportunity. Princeton University Press.

[6] Erhard, W., Jensen, M., \& Granger, K. (2011). Creating Leaders: An Ontological/Phenomenological Model. In S. Snook, N. Nohria, \& R. Khurana (Eds.), The Handbook for Teaching Leadership (pp. 245-262). Sage Publications.

[7] Fink, J.L. (2019). Phantasia in Aristotle's Ethics. Bloomsbury Publishing.

[8] Gordon, S. (2021). Addressing Unconscious Bias at Work. Wiley \& Sons Publishing.

[9] Halualani, R., Fassett, D. L., Morrison, J., \& Dodge, P. (2006). Between the structural and the personal: Situated sense-makings of 'race.' Communication \& Critical/Cultural Studies, 3, 70-93.

[10] Harman, W., \& Porter, M. (1997). The New business of business. Penguin Random House.

[11] Heath, R. L., Pierce, W. B., Shotter, J., Taylor, J. R., Zorn, T., Roper, J.,Deetz, S. (2006). The process of dialogue: Participation and legitimation. Management Communication Quarterly, 19(3), 341-375.

[12] Hoobler, J.M., Lemmon, G., Wayne, S.J. (2011). Women's underrepresentation in upper management: new insights on a persistent problem. Organizational Dynamics, 40(3), 151-156.

[13] Hunt, V., Prince, S., Dixon-Fyle, S., \& Yee, L. (2018). Delivering through diversity. McKinsey \& Company, 231.

[14] Lambouths, D, Scarborough, W, Holbrook, A. (2019). Who supports diversity policies? It depends on the policy. Harvard Business Review.

[15] Lipman, B. (2009). Why Is Language Vague? Language and Economics. In M. Basili, N. Dimitri, \& I. Gilboa (Eds.), Cognitive Processes and Economic Behavior. Routledge Publishing.

[16] Logan, N. (2021). "Breaking Down Barriers of the Past and Moving Toward Authentic DEI Adoption," in Pompper, D. (Eds.) Public Relations for Social Responsibility (Communicating Responsible Diversity, Equality, and Inclusion, Emerald Publishing Limited, 3-17.

[17] Noel, J. (2003). Phronesis and Phantasia: Teaching with Wisdom and Imagination. Journal of Philosophy of Education, 33(2).

[18] Pai, M. (2020). Men in global health, 'time to lean out.' Nature Microbiology Community.

[19] Paige, S. (2021). Time to decolonize aid: insights and lessons from a global consultation. Alliance for Peacebuilding. Retrieved https://www.peacedirect.org/wpcontent/uploads/2021/05/PD-Decolonising-Aid-Report.pdf.

[20] Perry, R. (2018). Belonging at Work: Everyday actions you can take to cultivate an inclusive organization. Rhodes Perry Consulting. 
[21] Pompper, D. (2021). (Eds). Public relations for social responsibility: Affirming DEI commitment with action. Emerald Publishing Limited.

[22] Ramasubramanian, S. Gonlin, V., \& Sousa, A. (2017). Facilitated difficult dialogues on racism: a goal- based approach. Journal of Applied Communication Research.

[23] Russell, D.C. (2012). Phronesis and the virtues. The Cambridge Companion to Aristotle's Nicomachean Ethics. Cambridge University Press.

[24] Schwabenland, C., \& Tomlinson, F. (2015). Shadows and light: Diversity Management as phantasmagoria. Human Relations, 68, 1913-1936.

[25] Simpson, J. L. (2008). The color-blind double bind: Whiteness and the (im) possibility of dialogue. Communication Theory, 18(1), 139-159.

[26] Slater, K. (2020). The 'glass cliff': how women and people of color are set up to fail in the workplace. Today.

[27] Slote, M. (2001). Morals from Motives. Oxford University Press.

[28] Souba, W.W., \& Souba, M.H. (2016). Leadership and the Limitations of Language. Open Journal of Leadership, 5, 39-50.

[29] Spranger, A.N. (2021). The Inclusive Leader's Toolkit. Policy and Practices for Equality in Education. IGI Global Publishing.

[30] Sue, D. W. (2013). Race talk: The psychology of racial dialogues. American Psychologist, 68(8), 663- 672.

[31] Sue, D. W., \& Constantine, M. G. (2007). Racial micro aggressors as instigators of difficult dialogues on race:
Implications for student affairs educators and students. College Student Affairs Journal, 26(2), 136-143.

[32] Winters, M. (2020). Inclusive Conversations: Fostering Equity, Empathy, and Belonging Across Differences. Berrett-Koehler Publishers.

[33] Worsham, K., Sylvester, R., Hales, G., McWilliams, K., \& Luseka, E. (2021). Leadership for SDG 6.2: Is diversity missing? Learning from Failure in Environmental and Public Health Research.

[34] Dr. Linda Ellington (2021), Leadership Disruption: Time to Reimagine Leadership Talent. IJBMR 9(2), 118-123. DOI: 10.37391/IJBMR.090203.https://ijbmr.forexjournal.co.in/archive /volume-9/ijbmr-090203.html

[35] Dr. Linda Ellington (2021), Hyper-Leading in an era of HyperChange. IJBMR 9(3), 268-273. DOI: 10.37391/IJBMR.090304.https://ijbmr.forexjournal.co.in/archive /volume-9/ijbmr-090304.html

[36] Denean Robinson (2020), Post- Crisis Leadership: How Leaders can Embrace Chaos. IJBMR 8(4), 117-119. DOI:

10.37391/IJBMR.080405. https://ijbmr.forexjournal.co.in/archive/volume-8/ijbmr080405.html

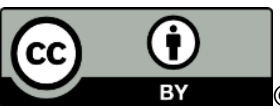

2021 by the Dr. Linda Ellington. Submitted for possible open access publication under the terms and conditions of the Creative Commons Attribution (CC BY) license (http://creativecommons.org/licenses/by/4.0/). 